
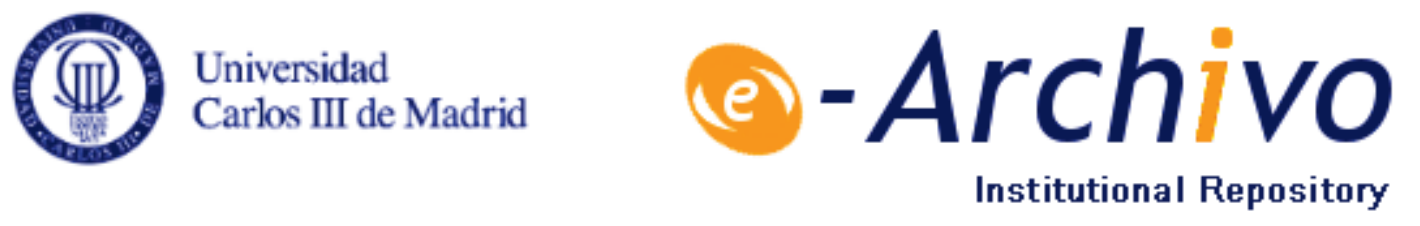

This is a postprint version of the following published document:

Velasco, F., Guzmán, S., Moral, C. (2013). Oxidation of Micro-Sized Aluminium Particles: Hollow Alumina Spheres. Oxidation of Metals, vol. 80, no. 3-4, pp. 403-422. Avalaible in http://dx.doi.org/10.1007/s11085013-9408-9.

(C) Springer Science + Business Media New York 


\title{
Oxidation of Micro-Sized Aluminium Particles: Hollow Alumina Spheres
}

\author{
F. Velasco • S. Guzmán • C. Moral • A. Bautista
}

\begin{abstract}
Oxidized aluminium microparticles have recently been proposed for manufacturing new, environmentally-friendly, protective coatings on stainlesssteels and Ni-base alloys. The oxidation mechanisms of spherical aluminium microparticles of an average particle size of $3.5 \mu \mathrm{m}$ were studied. Accordingly, simultaneous differential thermal analysis-thermogravimetry tests were carried out in air at different temperatures, always above aluminium melting temperature. Scanning electron microscopy and XRD were also used for the interpretation of results. Weight gain and energy results were explained in terms of the different structural changes taking place in aluminium particles. Dehydroxylation process was identified. The transformation of amorphous alumina to $\gamma-\mathrm{Al}_{2} \mathrm{O}_{3}$ was numerically evaluated and the alumina phase transformation $\left(\gamma-\mathrm{Al}_{2} \mathrm{O}_{3} \rightarrow \alpha-\mathrm{Al}_{2} \mathrm{O}_{3}\right)$ was also studied. The temperature ranges revealed the appearance of metastable phases $\left(\theta-\mathrm{Al}_{2} \mathrm{O}_{3}\right)$. Complete oxidation of particles can be obtained at $1,300{ }^{\circ} \mathrm{C}$ in $<1 \mathrm{~h}$, although this also takes place at lower temperatures if enough oxidation time is used. Activation energy of oxidation process at high temperature was also estimated, taking a value of $334 \mathrm{~kJ} / \mathrm{mol}$. High temperature oxidation causes the formation of hollow alumina spheres, without any aluminium left inside them.
\end{abstract}

Keywords Aluminium · Powder · Oxidation · Microparticles · Hollow spheres · Alumina

F. Velasco $(\bowtie) \cdot$ S. Guzmán · C. Moral · A. Bautista

Materials Science and Engineering Department, Universidad Carlos III de Madrid, Av Universidad 30, 28911 Leganés, Madrid, Spain

e-mail: fvelasco@ing.uc3m.es 


\section{Introduction}

Aluminium particles have two main applications at high temperature. The first is the development of slurries for oxidation protection of components at high temperature [1]. The majority of efforts has been devoted to the use of aluminium powder as an additive for propellants, explosives and pyrotechnics. For example, particle size influence on ignition temperatures for explosives has been summarised elsewhere [2], for temperatures ranging from 650 to $2,000{ }^{\circ} \mathrm{C}$.

There are several studies regarding the oxidation of aluminium particles. After manufacturing, an amorphous alumina layer covers these particles [3]. During heating in oxidizing conditions, this layer is transformed into crystalline alumina $\left(\gamma-\mathrm{Al}_{2} \mathrm{O}_{3}, \delta-\mathrm{Al}_{2} \mathrm{O}_{3}, \theta-\mathrm{Al}_{2} \mathrm{O}_{3}, \alpha-\mathrm{Al}_{2} \mathrm{O}_{3}\right)$, as temperature is increased. Particle size, oxidizing conditions and heating rate can all affect the transformations between the polymorphic phases.

Trunov et al. [2] studied the influence of the heating rate on different powders under pure oxygen flow for combustion processes using thermogravimetry (TG) and $\mathrm{X}$-ray diffraction (XRD). Higher heating rates shifted all the oxidation processes toward higher temperatures, with ignition temperatures depending on particle size. In addition, four oxidation stages were defined in this study.

Rufino et al. [4] carried out an analysis of micrometric and nanometric aluminium powders at temperatures up to $700{ }^{\circ} \mathrm{C}$, in inert conditions, using differential scanning calorimetry (DSC) and transmission electron microscopy (TEM). Some structural changes did not appear while strong particles aggregates did appear. A brief approach to oxidative conditions was carried out, through TG measurements in air, in temperatures up to $900{ }^{\circ} \mathrm{C}$, confirming Trunov's [2] results. Moreover, under oxidative conditions, coalescence of particles was reduced when compared to inert conditions [4].

Recently, a complete study [5] was published regarding the oxidation mechanisms of 100-200 $\mu \mathrm{m}$ aluminium particles, using TG, differential thermal analysis (DTA) and scanning electron microscopy (SEM). Different heating rates were studied, and $1,400{ }^{\circ} \mathrm{C}$ was selected as maximum temperature. Structural changes were confirmed and mechanisms of transformation were proposed. One of the main conclusions was that the complete oxidation of particles cannot be achieved.

Kinetic models for the oxidation of aluminium particles do not exist, except for a model related to ignition of aluminium particles [6]. There are, however, models regarding the thermal oxidation of two metal powders above their melting temperature: zinc [7] and indium [8].

This research was focused on the changes taking place in aluminium particles to be used in slurries to aluminize stainless steels and Ni-base superalloys [9-11]. A more environmentally-friendly approach for slurries is investigated within the European project "Particoat" [12], in which Al microparticles (1-20 $\mu \mathrm{m})$ are added to simple mixtures of water (solvent) and organic binders [13] with no additional chemical compounds. It is important to understand the behaviour of aluminium microparticles in air to understand the phenomena taking place during aluminizing. Although those transformations have been defined in previous cited works [2-5], they have not been studied for microparticles in air, up to $1,300{ }^{\circ} \mathrm{C}$. Furthermore, no 
SEM studies of aluminium microparticles have been included to show the changes in their morphology. Only Hasani et al. [5] have included SEM images, but for particles 100-times larger than those used in this study.

\section{Experimental Procedures}

Al microparticles (Sibthermochim, Russia) were produced using the wire explosion method [14], with an average particle size (D [3, 4]) of $3.50 \mu \mathrm{m}$. Particles are spherical, with a narrow particle size distribution $(\mathrm{D} 10=1.5 \mu \mathrm{m} ; \mathrm{D} 50=3.19 \mu \mathrm{m}$; $\mathrm{D} 90=6.18 \mu \mathrm{m}$ ). Their oxygen content was $0.42 \pm 0.03 \%$, typical for aluminium particles, and their specific surface, measured during sieve size analysis, was $1.70 \mathrm{~m}^{2} / \mathrm{g}$.

Thermal analysis of particles consisted of simultaneous TG and DTA analysis. Around $150 \mathrm{mg}$ of sample was placed into alumina crucibles. Thermal analysis was calibrated in temperature using the melting point of high purity metals ( $\mathrm{Sn}, \mathrm{Zn}, \mathrm{Al}$, $\mathrm{Ag}$ and $\mathrm{Au}$ ) samples under identical experimental conditions, resulting in a temperature accuracy of $\pm 1{ }^{\circ} \mathrm{C}$. Calibration in energy was done using enthalpies of fusion. All heating and cooling processes were carried out at $10{ }^{\circ} \mathrm{C} / \mathrm{min}$ in air. The air flow rate was $120 \mathrm{ml} / \mathrm{min}$. Different temperatures were used, ranging from 750 to $1,300{ }^{\circ} \mathrm{C}$, and from 1 to $24 \mathrm{~h}$ dwell-time. All tests were repeated at least three times in order to obtain accurate results. Shorter dwells $(15 \mathrm{~min})$ were also evaluated at the most critical temperatures $\left(950\right.$ and $1,050{ }^{\circ} \mathrm{C}$ ) to evaluate time dependence of alumina transformations.

In addition, consecutive heating-cooling processes were also carried out. The powders were heated at different temperatures (from 1,050 to $1,300{ }^{\circ} \mathrm{C}$ ). Each cycle consisted on a heating step at $10{ }^{\circ} \mathrm{C} / \mathrm{min}$ in air. Different dwell times were chosen depending on the oxidation temperature: $5 \mathrm{~h}$ (at 1050,1100 and $1150{ }^{\circ} \mathrm{C}$ ), $4 \mathrm{~h}$ $\left(1,200\right.$ and $\left.1,250{ }^{\circ} \mathrm{C}\right)$ and $1 \mathrm{~h}\left(1,300{ }^{\circ} \mathrm{C}\right)$. After dwell, powders were cooled at $10{ }^{\circ} \mathrm{C} / \mathrm{min}$ to $475{ }^{\circ} \mathrm{C}$ (below aluminium melting temperature) and immediately powders were heated again following the same cycle. DTA signal was analysed in terms of melting and solidification of aluminium. Global testing times (time at high temperature dwell) were: $75 \mathrm{~h}$ (for $1,050{ }^{\circ} \mathrm{C}$ ), $60 \mathrm{~h}$ (for 1,100 and $1,150{ }^{\circ} \mathrm{C}$ ), $48 \mathrm{~h}$ (for $1,200{ }^{\circ} \mathrm{C}$ ), $40 \mathrm{~h}$ (for $1,250{ }^{\circ} \mathrm{C}$ ) and $7 \mathrm{~h}$ (for $1,300{ }^{\circ} \mathrm{C}$ ).

Moreover, long-term tests were also carried out to find theoretical full oxidation times of aluminium powders, at temperatures ranging from 1,200 to $1,325^{\circ} \mathrm{C}$.

The microstructure of the oxidized powders was analyzed by SEM, and XRD was carried out for different oxidized powders.

\section{Results and Discussion}

TG oxidation tests of aluminium particles show very small differences when they are carried out under the same conditions. Figure 1 shows 6 different oxidation tests done at $850{ }^{\circ} \mathrm{C}$ for different dwell times, ranging from 1 to $24 \mathrm{~h}$. Negligible differences are found among them, which are related to the particle size distribution. 
As previously indicated, particle size distribution is very narrow, and the repetitivity of the tests is then assured. The reproducibility of the results was checked for all the studied temperatures.

The weight gains at different temperatures (isothermal dwells) can be found in Fig. 2. It can be clearly appreciated that increasing oxidation temperature increases weight gain, as expected. The oxidation process increases with temperature, as found in other alumina scales [15]. Those results can be clearly related to the phases present at each temperature, detected through XRD (Fig. 3).

At $750{ }^{\circ} \mathrm{C}, \gamma-\mathrm{Al}_{2} \mathrm{O}_{3}$ (JCPDS 29-0063) can be found (Fig. 3a). Slow weight gain occurs, as a stable $\gamma-\mathrm{Al}_{2} \mathrm{O}_{3}$ layer is found. Smooth particles are found (Fig. 4 up) after oxidation at this temperature, due to the stability of the oxide layer and the still low temperatures of oxidation. Especially remarkable are the results obtained at $850{ }^{\circ} \mathrm{C}$, where kinetics is faster (Fig. 2). This is clearly related to the presence of $\theta-\mathrm{Al}_{2} \mathrm{O}_{3}$, as XRD pattern (Fig. 3b) shows. This phase has no protection ability, provoking the important mass gains found at this temperature. Together with $\theta-\mathrm{Al}_{2} \mathrm{O}_{3}$ (JCPDS 23-1009), $\alpha-\mathrm{Al}_{2} \mathrm{O}_{3}$ (JCPDS 43-1484) appears, although in a small amount. Particles are still smooth (Fig. 4 down), and they are filled with non-reacted aluminium, molten at the tested temperatures and solid at room temperature as shown in XRD (Fig. 3a, b, JCPDS 04-0787). At those temperatures (750 and $850{ }^{\circ} \mathrm{C}$ ), logarithmic kinetics is found, following Eq. 1:

$$
\mathrm{y}=\mathrm{a}+\mathrm{b} \ln (\mathrm{t}+\mathrm{c})
$$

where $y$ is the weight gain (in \%) and $t$ is the time. The values of the $b$ parameter (in $\%$ by mass) are directly related to the aggressivity of the oxidation process at the

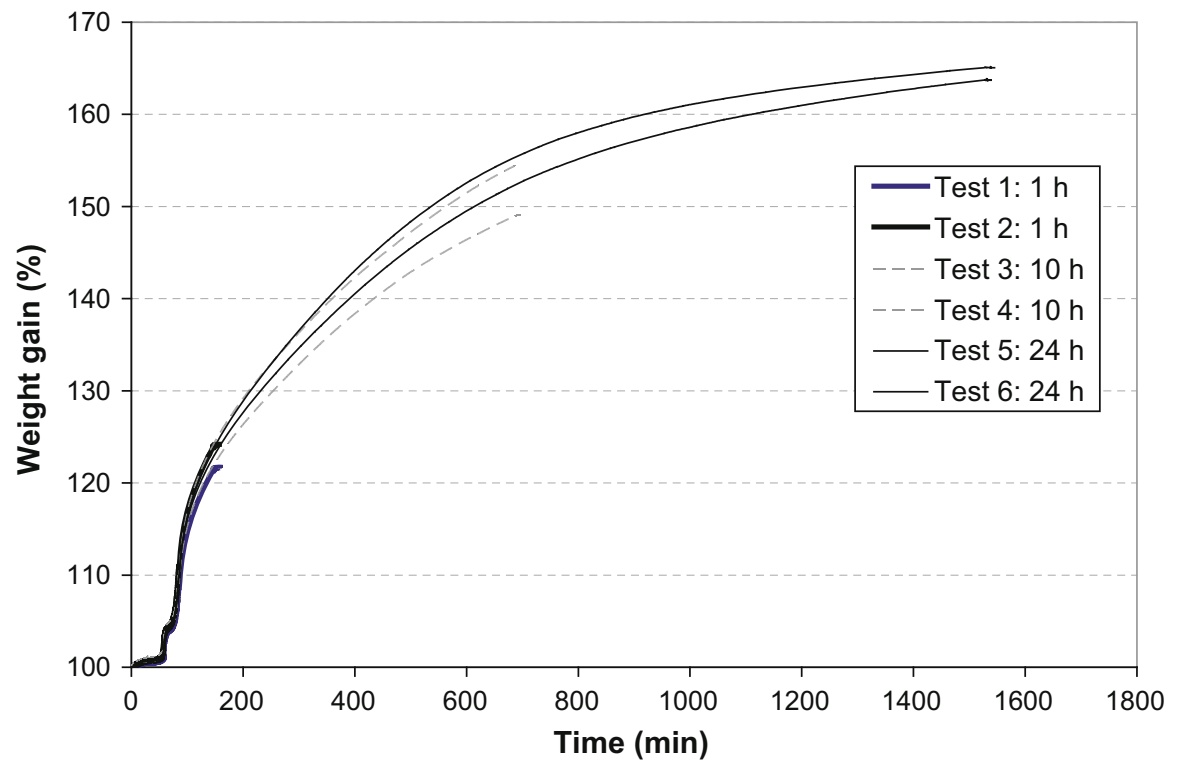

Fig. 1 TG gains of aluminium powders during heating at $850{ }^{\circ} \mathrm{C}$, for different dwell times 


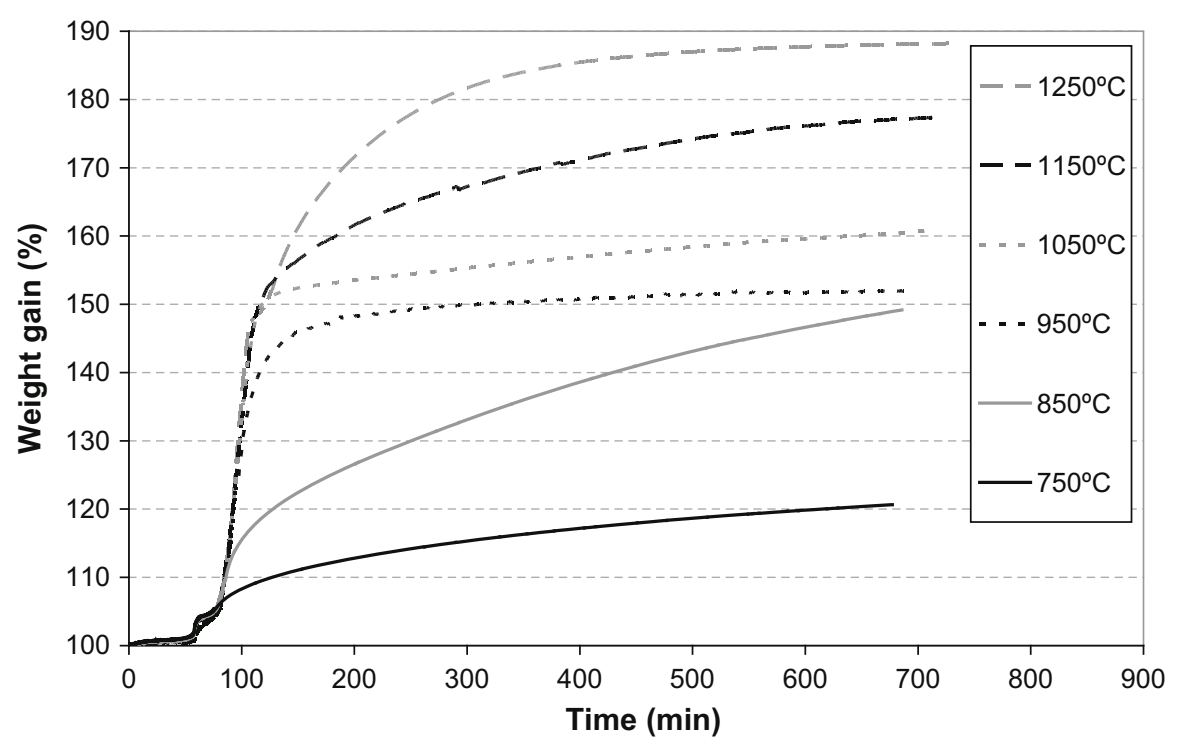

Fig. 2 Weight gains during $10 \mathrm{~h}$ isothermal dwells

given temperature. $a$ and $c$ parameters are useful to fit the mass gain that occurs during the heating ramp, that is also done in air. The adjustments are good (high values of $R^{2}$ ).

This kinetics is typical of highly protective scales on wrought metals at low oxidation temperatures. Besides, it has been related to the presence of cavities or precipitates that hinder diffusion in non-porous materials with thick scales. For instance, logarithmic rate behaviour has been detected when partial scale detachment inhibits pre-existing scale growth mechanism or when very stable particles grow within the scale or at the metal/scale interface and restrict the growth of a much faster growing oxide [16]. Those are examples where exposed area changes during oxidative attack. This has been also demonstrated for powder metallurgy stainless exposed at high-temperature exposure [17-19]. Initially, oxidation affects the whole surface of the porous material. After certain time, oxide fills the smallest pores and the attack must be almost stopped in these areas. The complex morphology of porous surface exposed to the attack and their partial blocking by the oxidation products justifies the logarithmic (or asymptotic) kinetics. Aluminium particles have much surface to be oxidized, and it is reduced significantly during exposure time, so logarithmic adjustments fits better than typical parabolic or sub parabolic kinetics observed for rolled samples [20].

As can be seen in Table 1, the value of $b$ increases when oxidation temperature does (from 750 to $850{ }^{\circ} \mathrm{C}$ ). This behaviour was expected from TG curves (Fig. 2) and XRD patterns (Fig. 3a, b). The phases appearing at those temperatures are different $\left(\gamma-\mathrm{Al}_{2} \mathrm{O}_{3}\right.$ at $750{ }^{\circ} \mathrm{C}, \theta-\mathrm{Al}_{2} \mathrm{O}_{3}$ and $\alpha-\mathrm{Al}_{2} \mathrm{O}_{3}$ at $\left.850{ }^{\circ} \mathrm{C}\right)$ making clear this difference. 

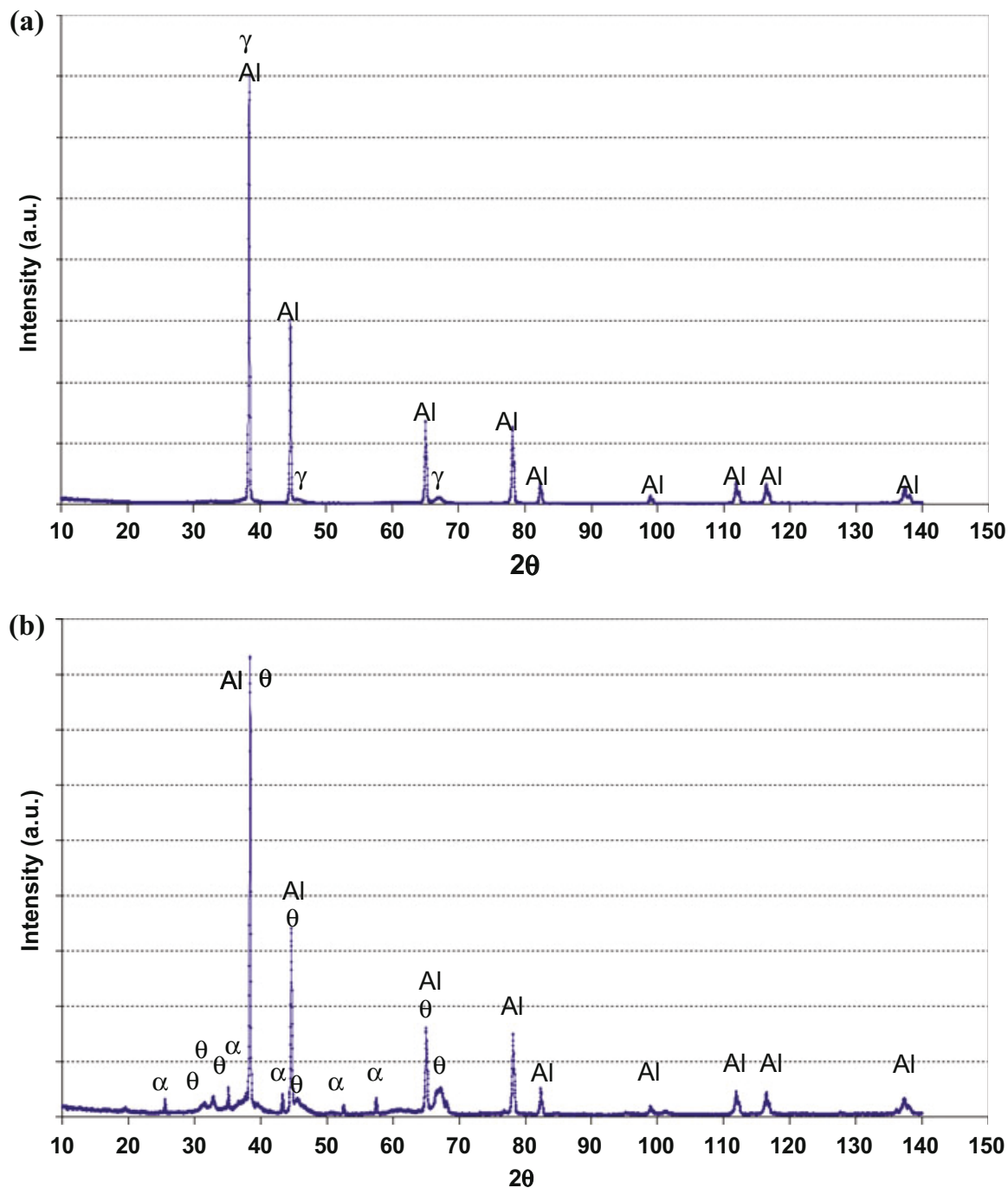

Fig. 3 XRD patterns of powders after oxidation at different temperatures for $10 \mathrm{~h}: \mathbf{a} 750{ }^{\circ} \mathrm{C}$; b $850{ }^{\circ} \mathrm{C}$; c $950{ }^{\circ} \mathrm{C} ; \mathbf{d} 1,150{ }^{\circ} \mathrm{C}$

At $950{ }^{\circ} \mathrm{C}, \alpha-\mathrm{Al}_{2} \mathrm{O}_{3}$ grows quite fast, and the protection of the spheres increases, being mass gain rate quite slow, and comparable to $850{ }^{\circ} \mathrm{C}$ (Fig. 2). However, $\alpha-\mathrm{Al}_{2} \mathrm{O}_{3}$ presence (Fig. 3c) is bigger than at $850{ }^{\circ} \mathrm{C}$, and the amount of $\alpha-\mathrm{Al}_{2} \mathrm{O}_{3}$ is much more than that of $\theta-\mathrm{Al}_{2} \mathrm{O}_{3}$. This suggests that the spheres are oxidizing at a slow rate. The cubic-FCC disordered structure of $\gamma-\mathrm{Al}_{2} \mathrm{O}_{3}$ transforms into the hexagonal close packed ordered structure of $\alpha-\mathrm{Al}_{2} \mathrm{O}_{3}$, with a volume shrinkage of $13.8 \%$ [5]. The microstructural analysis (Fig. 5) shows the microstructure of particles after $10 \mathrm{~h}$ at $950{ }^{\circ} \mathrm{C}$. Alumina needles going out from aluminium particles can be clearly appreciated, leading to whisker morphologies. Different explanations 

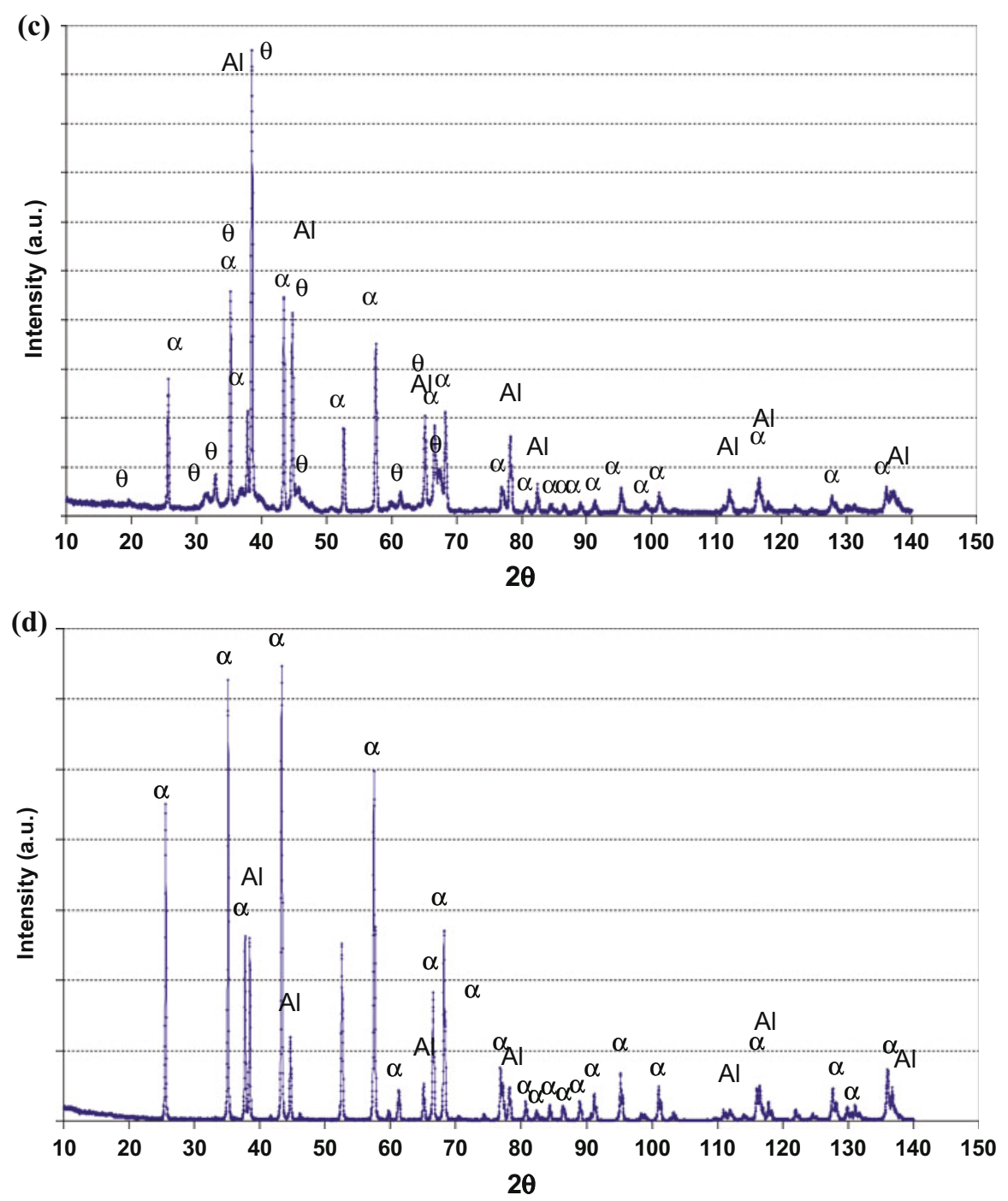

Fig. 3 continued

can exist related to these whiskers. It has been demonstrated that local growth of $\theta-\mathrm{Al}_{2} \mathrm{O}_{3}$ can present whisker morphology on wrought $\mathrm{NiAl}$ alloys [21] and $\mathrm{Fe} 25 \mathrm{Al}$ [22] and Fe40Al [23] strips. It has also been found in aluminized and annealed titanium [24]. The fact of having aluminium powders with molten aluminium inside could suggest a different, not-verified mechanism. Pores and nano-cracks form in the alumina scale during high-temperature transformation. Molten Al can penetrate outside through these pores and cracks being immediately oxidised when coming in contact with air. 

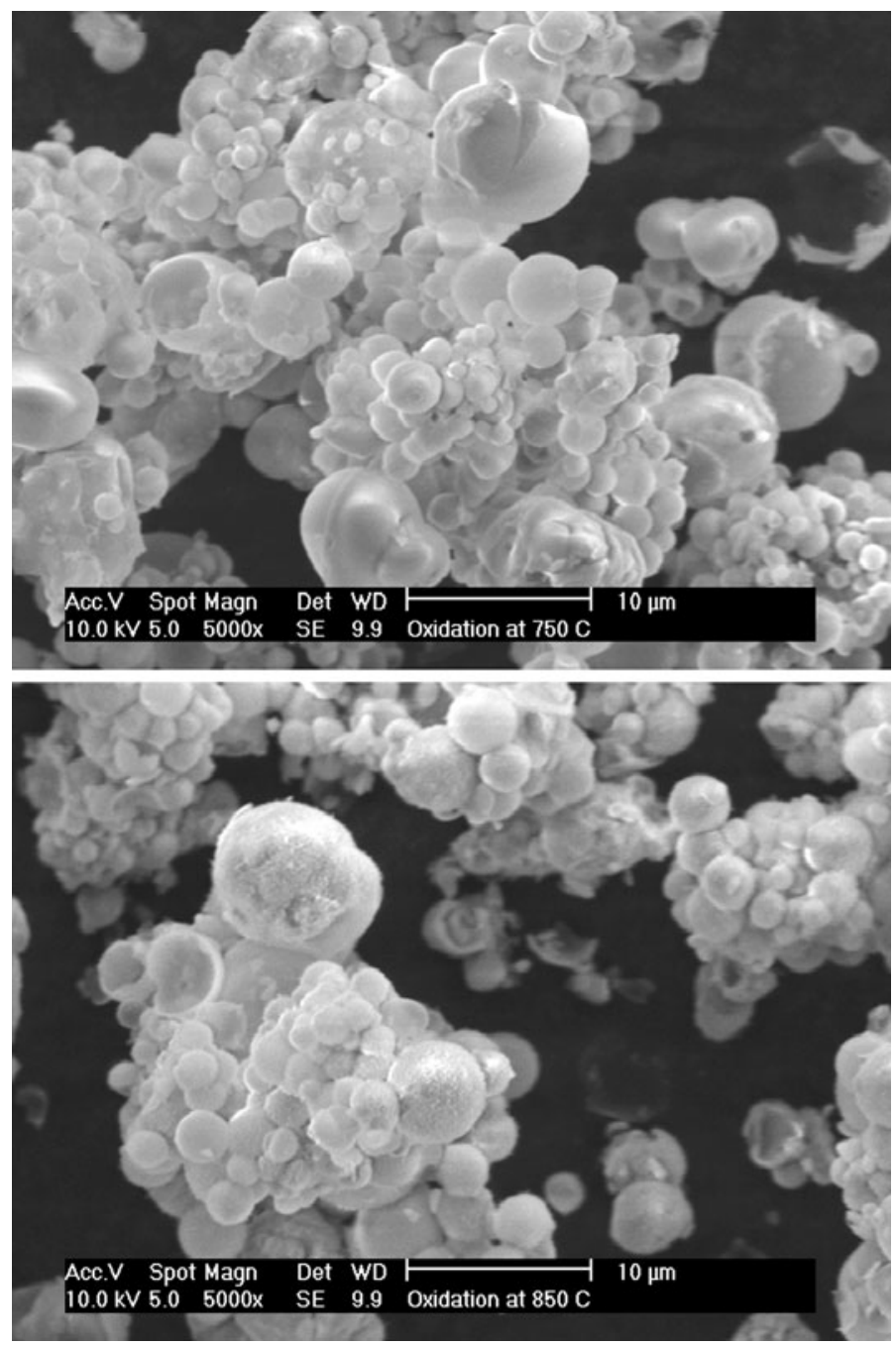

Fig. 4 SEM of aluminium powders after heating at $750{ }^{\circ} \mathrm{C}$ (up) and $850{ }^{\circ} \mathrm{C}$ (down) for $10 \mathrm{~h}$

Table 1 Kinetic of aluminium powders oxidised at 750 and $850{ }^{\circ} \mathrm{C}$ : b parameter and goodness of fitting of logarithmic adjustment (Eq. 1)

\begin{tabular}{lrr}
\hline Temperature $\left({ }^{\circ} \mathrm{C}\right)$ & $\mathrm{b}$ & $\mathrm{R}^{2}$ \\
\hline 750 & 6.19 & 99.92 \\
850 & 21.29 & 99.81 \\
\hline
\end{tabular}

Moreover, small hollow particles are also found. Those hollow spheres have completely lost the aluminium inside them, being the smaller particles of the sieve size distribution, and their alumina crust is broken. The alumina scale has not been 

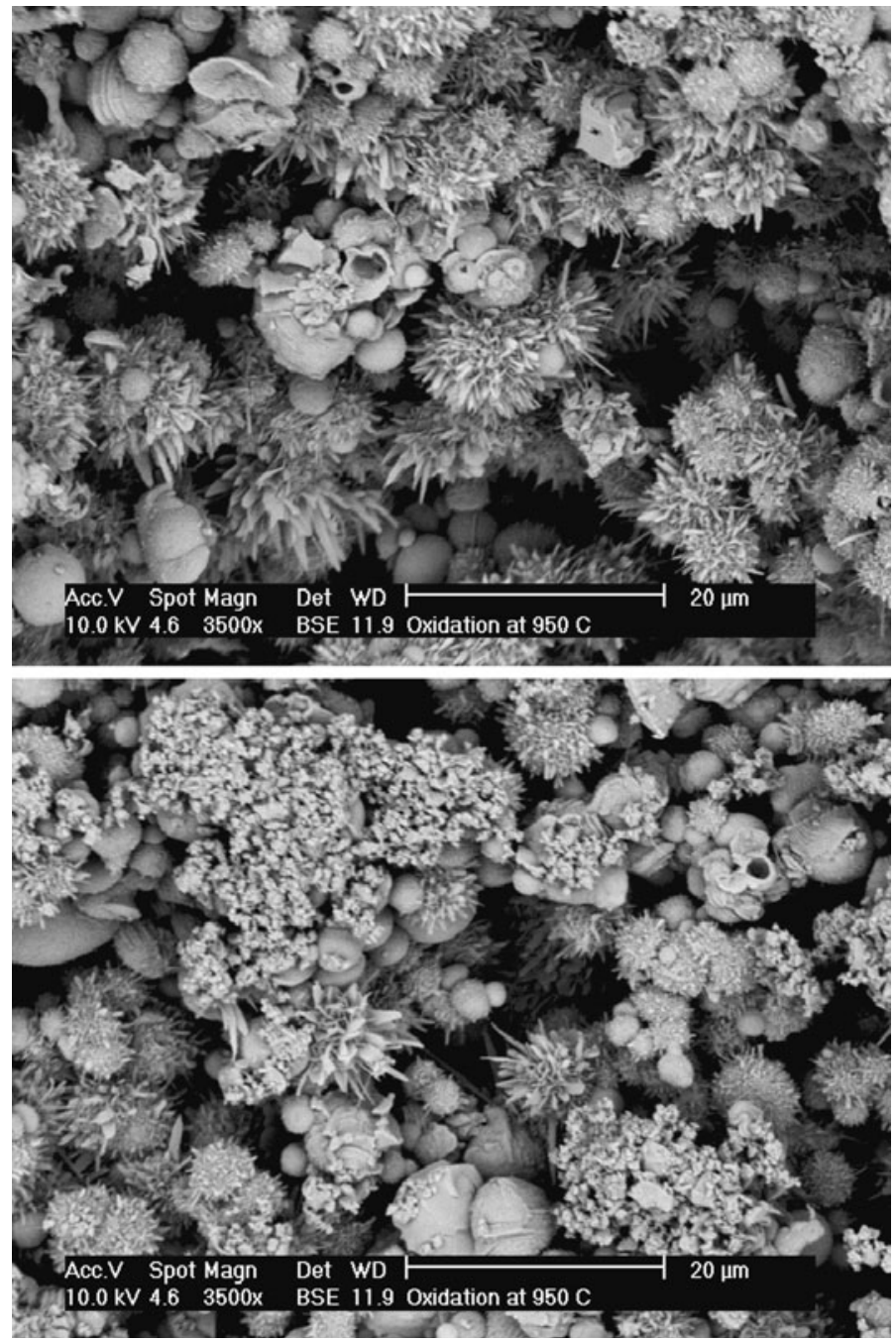

Fig. 5 SEM of aluminium powders after heating at $950{ }^{\circ} \mathrm{C}$ for $10 \mathrm{~h}$

able to withstand the stresses due to the shrinkage during the transformation. This would be in agreement with Kolarik et al. [25], who suggest $\theta-\mathrm{Al}_{2} \mathrm{O}_{3}$ disappears at these temperatures using in situ XRD techniques. Another possibility is a mechanical damage during cooling: smaller particles will lead to thinner scales that are not able to withstand mechanical stresses due to temperature drop during cooling. At this oxidation temperature $\left(950^{\circ} \mathrm{C}\right)$, it has not been possible to fit typical oxidation kinetics (pseudoparabolic, asymptotic, logarithmic) or others used for powders at high temperatures [7, 8]. This can be related to the polymorphic transformations taken place at this temperature. 
From $1,050{ }^{\circ} \mathrm{C}$, only $\alpha-\mathrm{Al}_{2} \mathrm{O}_{3}$ growth occurs (Fig. 3d). XRD patterns only differ in the amount of aluminium, as the oxidation increases with temperature (Fig. 2). The microstructure of particles oxidized at 1,050 and $1,150{ }^{\circ} \mathrm{C}$ (Fig. 6) is completely different. Alumina whiskers are not found, as they are formed at lower temperatures. Hollow alumina spheres are found, with aluminium inside them (molten and solidified, as oxidation is not complete at this temperature, Fig. 2). In addition, torn particles can be appreciated. At $1,250{ }^{\circ} \mathrm{C}$, the weight gain is the maximum attainable, according to the stoichiometric reaction of aluminium oxidation. For bigger particles (100-200 $\mu \mathrm{m})$, it has been reported that complete oxidation process does not take place even up to $1,400{ }^{\circ} \mathrm{C}$ [5]. After oxidation at $1,250{ }^{\circ} \mathrm{C}$ (Fig. 7), aluminium particles form complete hollow spheres, and no aluminium can be found inside any particle. This was the main objective for the application of Particoat [12] technology to manufacture coatings with thermal barrier effect. This agrees with the TG analysis (Fig. 2). Some sintering has taken place among particles, and some particles are broken, due to the thermal stresses and phase transformations occurring during heating, as previously indicated. The observation of broken particles at these high temperatures (Figs. 6, 7) could indicate that the failure of particles during cooling is the main mechanism as thicker oxide scales are present and greater particle contraction upon cooling takes place.

Kinetics at 1,050 and $1,150{ }^{\circ} \mathrm{C}$ are still logarithmic (Eq. 1 ), as found at lower temperatures. The values of $b$ parameter increase (Table 2), as expected, when increasing the temperature, although it can not be compared to 750 and $850{ }^{\circ} \mathrm{C}$ as another phase is being formed. At these high temperatures (Table 2), the fitting explains the oxidation rate to $\alpha-\mathrm{Al}_{2} \mathrm{O}_{3}$; however, fitting shown in Table 1 gives data regarding the oxidation rates when $\gamma-\mathrm{Al}_{2} \mathrm{O}_{3}$ and $\theta-\mathrm{Al}_{2} \mathrm{O}_{3}$ are also present. Fitting of aluminium powders oxidized at $1,250{ }^{\circ} \mathrm{C}$ was done using an asymptotic law (Eq. 2.), where $y$ is the weight gain (in $\%$ ) and $t$ is the time:

$$
\mathrm{y}=\mathrm{k}\left(1-\mathrm{e}^{\mathrm{dt}}\right)
$$

The reasons for this adjustment are the same as previously stated for Eq. 1. At this temperature, curve was displaced to the origin to obtain constant rate value and adequate fitting accordingly to equation. The adjustments are good (being $\mathrm{R}^{2}$ 99.68). The values of $k$ (constant rate, in \% by mass) and $d$ are 35.69 and 0.0106 respectively. This change in kinetics (from logarithmic to asymptotic) agrees with the fact of finding complete oxidation of particles at $1,250{ }^{\circ} \mathrm{C}$.

Alumina phase transformations are not only temperature but time dependant. XRD (Fig. 3) and SEM (Figs. 4, 5, 6, 7) results are obtained after $10 \mathrm{~h}$ exposure at different temperatures. Oxidation tests for shorter times were carried out in the critical temperature range $\left(950-1,050{ }^{\circ} \mathrm{C}\right)$ to find out the time dependence of phase transformations. Table 3 summarises the results. Intensity peaks of the main peaks of the three interesting phases (aluminium, $\theta-\mathrm{Al}_{2} \mathrm{O}_{3}$ and $\alpha-\mathrm{Al}_{2} \mathrm{O}_{3}$ ) are compared for tested conditions. The first noticeable data is the absence of $\theta-\mathrm{Al}_{2} \mathrm{O}_{3}$ in aluminium powders treated at $1,050{ }^{\circ} \mathrm{C}$ for any time, while it is present in those treated at $950{ }^{\circ} \mathrm{C}$. Moreover, its amount is reduced with time, increasing the quantity of $\alpha-\mathrm{Al}_{2} \mathrm{O}_{3}$. This agrees with TG data (Fig. 3): at the initial stages at $950{ }^{\circ} \mathrm{C}$, reaction rate is much faster than at longer times. $\theta-\mathrm{Al}_{2} \mathrm{O}_{3}$ is mainly formed initially, in 

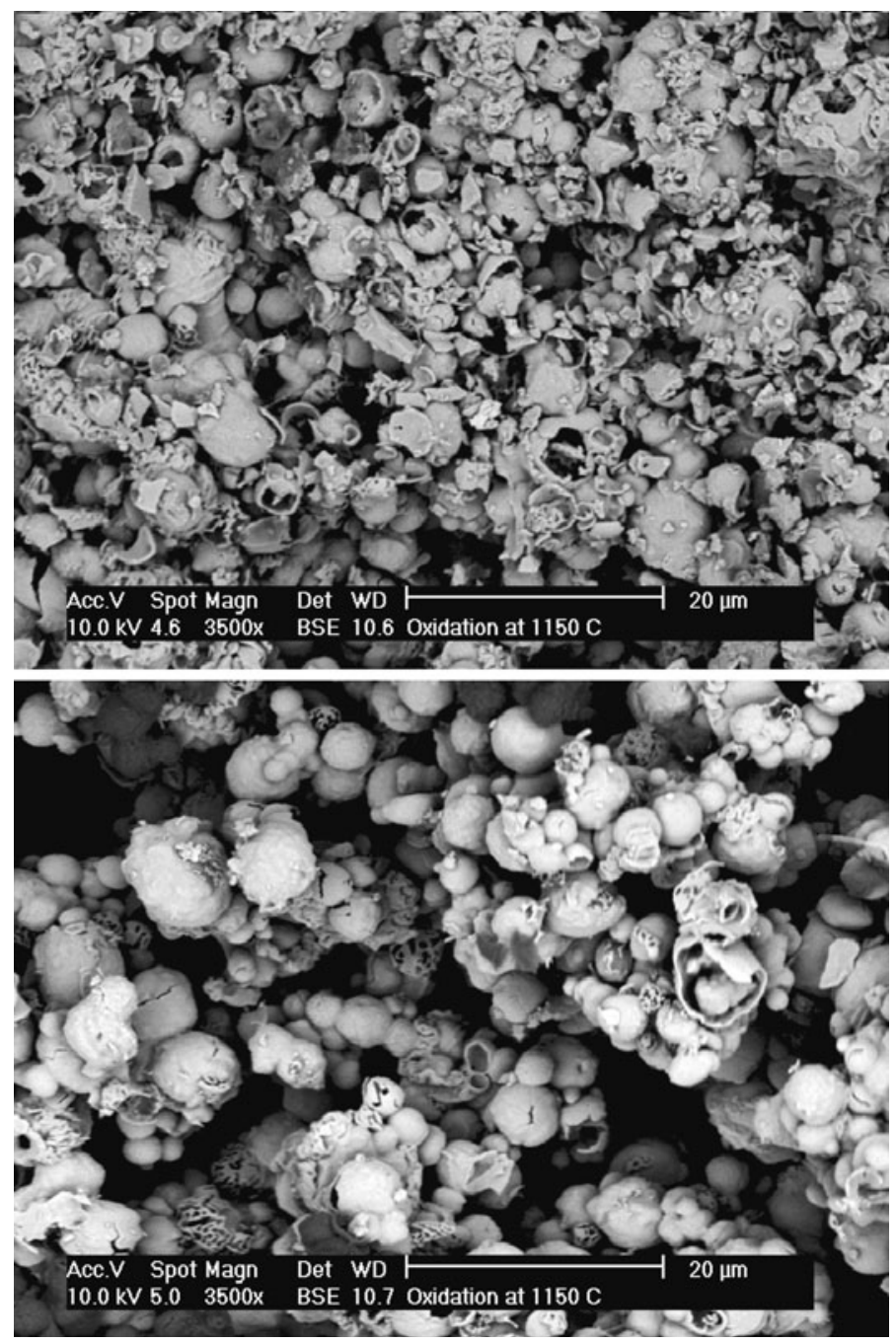

Fig. 6 SEM of aluminium powders after heating at $1,150{ }^{\circ} \mathrm{C}$ for $10 \mathrm{~h}$

particular at this temperature $\left(950{ }^{\circ} \mathrm{C}\right)$. This process would take be faster than at lower temperatures (i.e., $850{ }^{\circ} \mathrm{C}$ ), but the transformation from $\theta-\mathrm{Al}_{2} \mathrm{O}_{3}$ to $\alpha-\mathrm{Al}_{2} \mathrm{O}_{3}$ will also be faster at $950{ }^{\circ} \mathrm{C}$, as it has been previously observed [26]. Moreover, the transformation of aluminium is observed at both temperatures. The comparison shows the growth of $\alpha-\mathrm{Al}_{2} \mathrm{O}_{3}$ with time, as expected.

Figure 8 shows the TG-DTA analysis of powders during heating up to $950{ }^{\circ} \mathrm{C}$, where most important reactions take place. The process taking place at $250-300{ }^{\circ} \mathrm{C}$ can be related to the desorption of water from the surface of the particles and the subsequent dehydroxylation of the aluminol groups contained in the amorphous layer surrounding the aluminium particles $[4,13]$. Aluminium particles are covered 

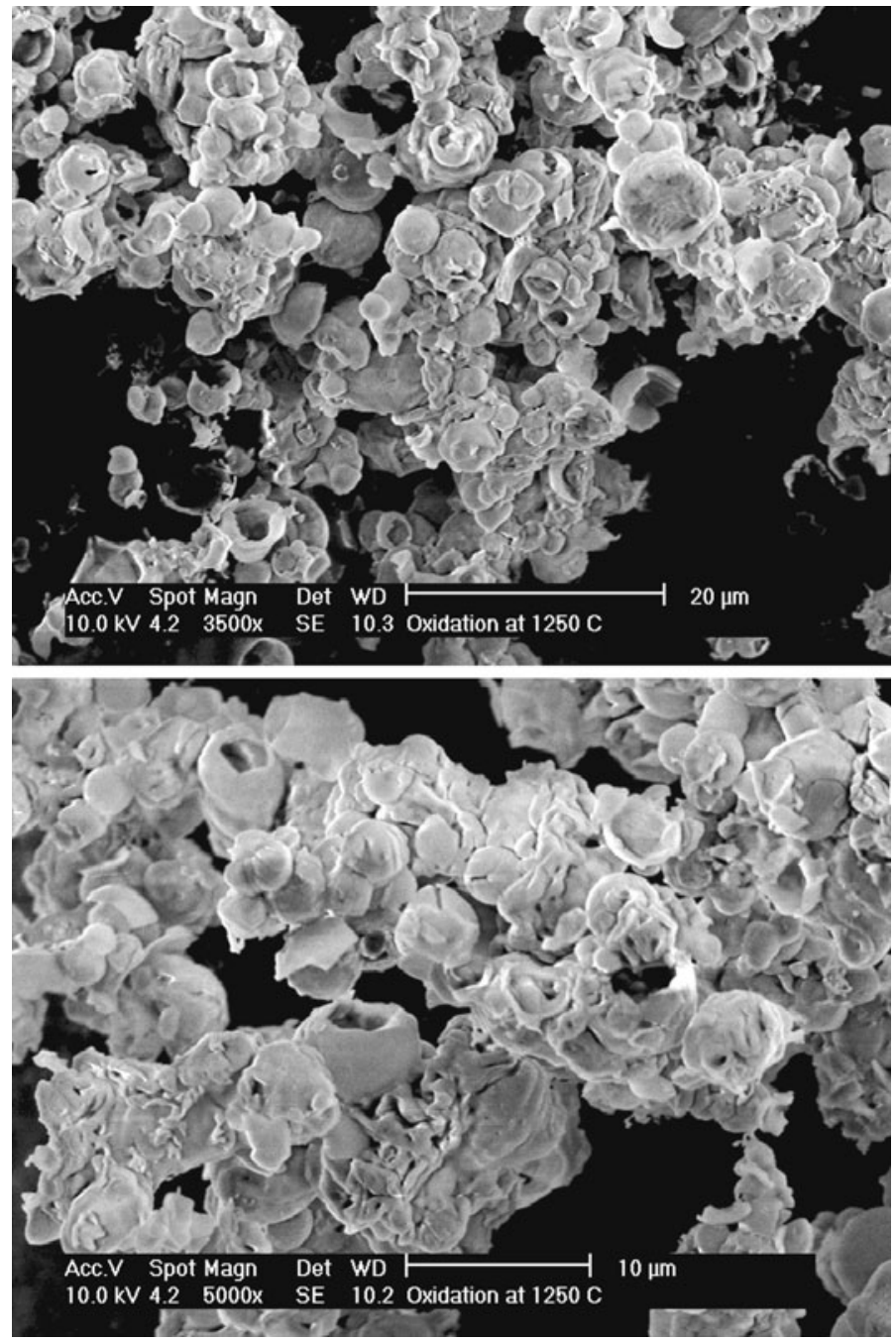

Fig. 7 SEM of aluminium powders after heating at $1,250{ }^{\circ} \mathrm{C}$ for $10 \mathrm{~h}$

Table 2 Kinetic of aluminium powders oxidised at 1,050 and $1,150{ }^{\circ} \mathrm{C}$ : b parameter and goodness of fitting of logarithmic adjustment (Eq. 1)

\begin{tabular}{lrr}
\hline Temperature $\left({ }^{\circ} \mathrm{C}\right)$ & $\mathrm{b}$ & $\mathrm{R}^{2}$ \\
\hline 1,050 & 4.86 & 96.12 \\
1,150 & 10.18 & 99.89 \\
\hline
\end{tabular}

by a nanometric, amorphous layer of alumina after production processes. A change of the DTA slopes takes place from $450{ }^{\circ} \mathrm{C}$. For the micrometric particle size used, weight gains at this stage are small but measurable. Other researchers have not 
Table 3 Intensity ratios of several XRD peaks from patterns obtained with aluminium powders oxidised at 950 and $1,050{ }^{\circ} \mathrm{C}$ for different times

\begin{tabular}{|c|c|c|c|c|c|c|}
\hline & \multicolumn{3}{|l|}{$950{ }^{\circ} \mathrm{C}$} & \multicolumn{3}{|c|}{$1,050{ }^{\circ} \mathrm{C}$} \\
\hline & $15 \mathrm{~min}$ & $1 \mathrm{~h}$ & $10 \mathrm{~h}$ & $15 \mathrm{~min}$ & $1 \mathrm{~h}$ & $10 \mathrm{~h}$ \\
\hline$\theta-\mathrm{Al}_{2} \mathrm{O}_{3}(403) / \alpha-\mathrm{Al}_{2} \mathrm{O}_{3}(113)$ & 1.80 & 0.25 & 0.18 & - & - & - \\
\hline$\theta-\mathrm{Al}_{2} \mathrm{O}_{3}(-401) / \alpha-\mathrm{Al}_{2} \mathrm{O}_{3}(113)$ & 0.35 & 0.09 & 0.06 & - & - & - \\
\hline $\mathrm{Al}(111) / \alpha-\mathrm{Al}_{2} \mathrm{O}_{3}(113)$ & 60.4 & 10.5 & 2.1 & 2.9 & 2.8 & 1.0 \\
\hline $\mathrm{Al}(111) / \alpha-\mathrm{Al}_{2} \mathrm{O}_{3}(104)$ & 100.7 & 11.3 & 2.2 & 3.0 & 2.7 & 1.0 \\
\hline
\end{tabular}

Crystallographic data of used peaks is included

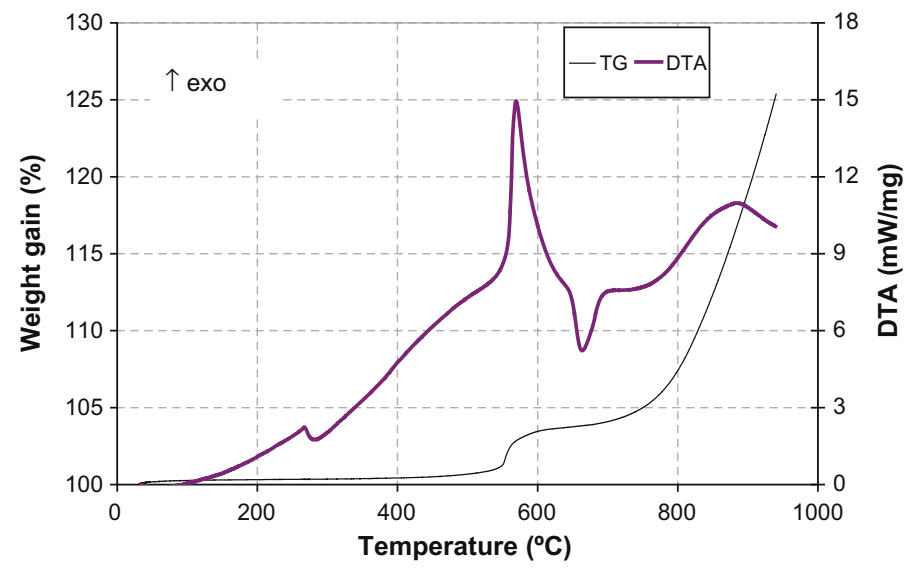

Fig. 8 TG/DTA simultaneous analysis of aluminium powders during heating to $950{ }^{\circ} \mathrm{C}$

found this transformation when protective argon atmospheres are used [4]. From weight gain results and specific surface measurement of aluminium powders, and assuming a density for amorphous alumina of $3.05 \mathrm{~g} / \mathrm{cm}^{3}$, the maximum thickness of amorphous alumina layer at this stage can be estimated to be around $4.7 \mathrm{~nm}$ (value in the range of [2]). This value was obtained at the inflection point of TG curves $\left(540{ }^{\circ} \mathrm{C}\right.$ approximately).

A strong exothermal reaction occurs at $540{ }^{\circ} \mathrm{C}$ (Fig. 8). This reaction takes place with an important, stepwise weight gain. The range of temperatures is very narrow: from $540 \pm 5$ to $617 \pm 5{ }^{\circ} \mathrm{C}$ (data from 16 randomly selected runs). At this temperature $\left(540{ }^{\circ} \mathrm{C}\right)$, the thickness of the amorphous alumina layer reaches a critical value so a thermodynamically more stable, crystalline aluminium oxide $\left(\gamma-\mathrm{Al}_{2} \mathrm{O}_{3}\right)$ is formed. According to [3], the transformation of amorphous to crystalline alumina takes place at a critical thickness below $5 \mathrm{~nm}$ for aluminium sheets. This value is in accordance with that evaluated at the end of the previous step. This allows the formation of a thicker, more stable oxide on the surface of particles. From the weight gain and the specific surface characteristic of aluminium powders, and assuming a density of $3.66 \mathrm{~g} / \mathrm{cm}^{3}$ for $\gamma-\mathrm{Al}_{2} \mathrm{O}_{3}$, the thickness of 
alumina layer at the end of this stage can be estimated to be around $12 \mathrm{~nm}$. Those results are consistent with those appearing in similar size particles under pure oxygen [2]. The growth of the alumina layer and its change from amorphous to crystalline structure seem to occur simultaneously, as suggested in [4].

The heat associated to this reaction (amorphous $\mathrm{Al}_{2} \mathrm{O}_{3} \rightarrow \gamma-\mathrm{Al}_{2} \mathrm{O}_{3}$ ) is $954 \pm 70 \mathrm{~J} / \mathrm{g}$, being calculated with $95 \%$ accuracy. This value disagrees with the model developed by Trunov et al. [6]. These authors calculated, from TG studies, an activation energy from amorphous to $\gamma$ phase of $525 \mathrm{~kJ} / \mathrm{mol}$ (about 5 times bigger). However, these same researchers [27] have indicated that those activation energies are strictly valid for the specific particle oxidation model developed. Our results are consistent with the isoconversion analysis [27] performed, with the measured value being within the values they suggest. TG and DTA derivatives give more information regarding to this transformation. Maximum weight gain rate $(1.34 \% / \mathrm{min})$ takes place at $557{ }^{\circ} \mathrm{C}$ while maximum heat transfer rate $(7.8 \mathrm{~mW} / \mathrm{mg} / \mathrm{min})$ occurs at $560{ }^{\circ} \mathrm{C}$ (Fig. 9).

Melting of aluminium inside particles is then found (Fig. 8), characterized by the endothermic peak at $660{ }^{\circ} \mathrm{C}$ (approximately). The heat associated to this reaction is $382 \pm 38 \mathrm{~J} / \mathrm{g}$, being calculated with $95 \%$ accuracy. The latent heat of fusion aluminium is $398 \mathrm{~J} / \mathrm{g}$. The slight difference between data can be related to the presence of the alumina layer outside of the particles, which could reduce heat transfer. Moreover, some aluminium has been transformed into $\mathrm{Al}_{2} \mathrm{O}_{3}$, so the amount of aluminium is lower than that measured at the start of the experiment. Molten aluminium is kept within an alumina shell at those temperatures.

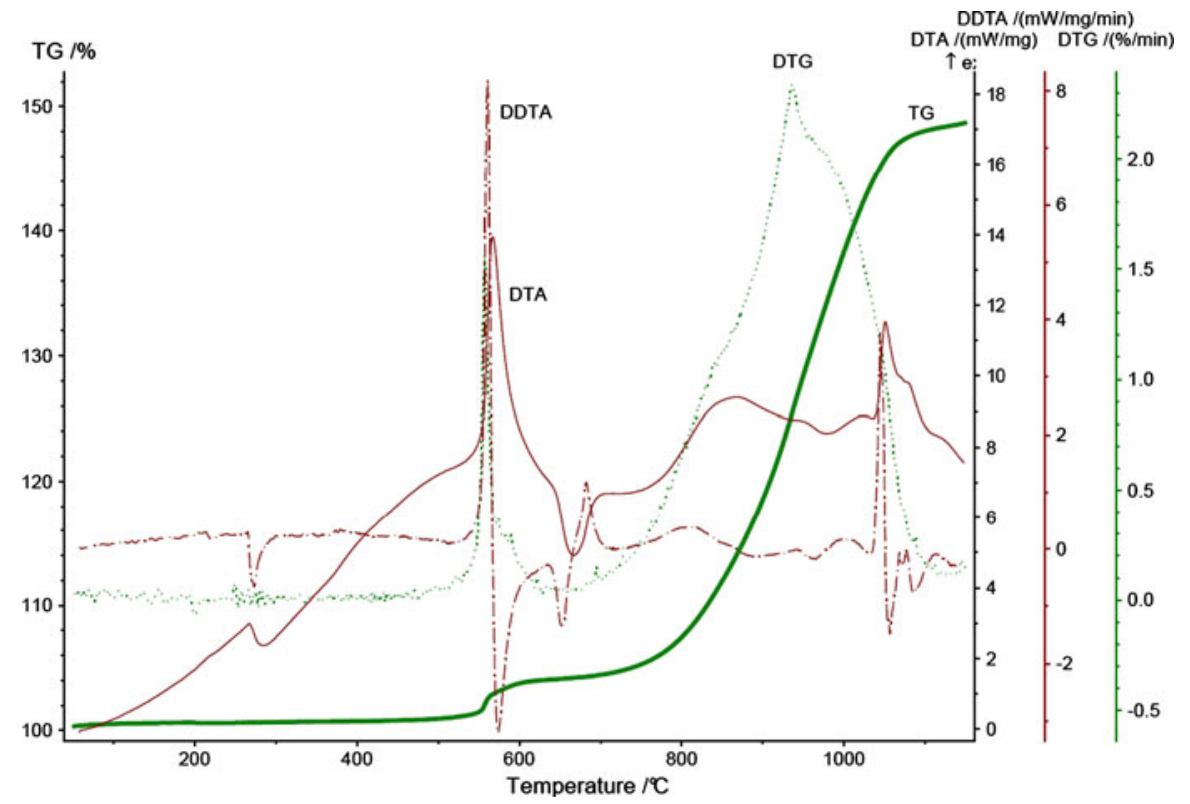

Fig. 9 TG/DTA simultaneous analysis of aluminium powders during heating to $1,150{ }^{\circ} \mathrm{C}$, and their first derivatives 


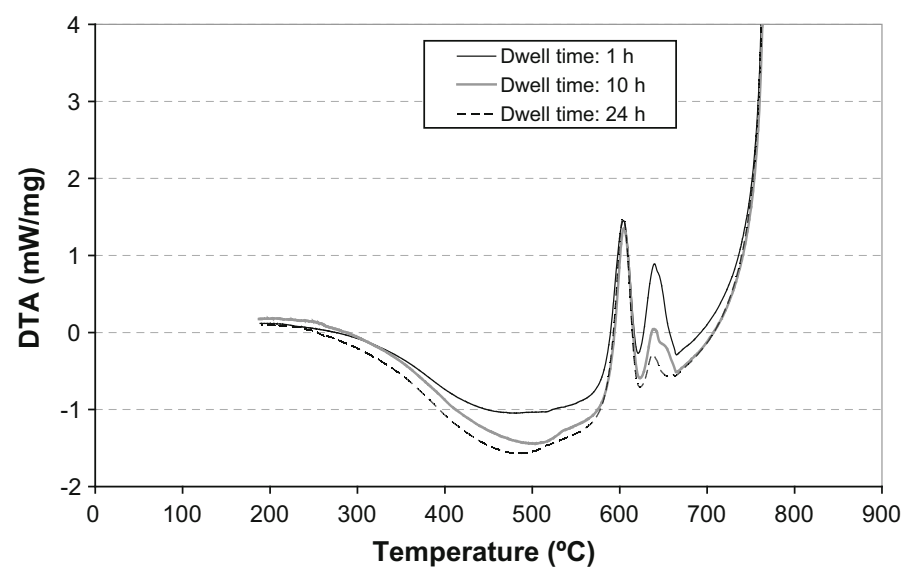

Fig. 10 DTA curves during cooling for aluminium powders heated at $750{ }^{\circ} \mathrm{C}$ for different times

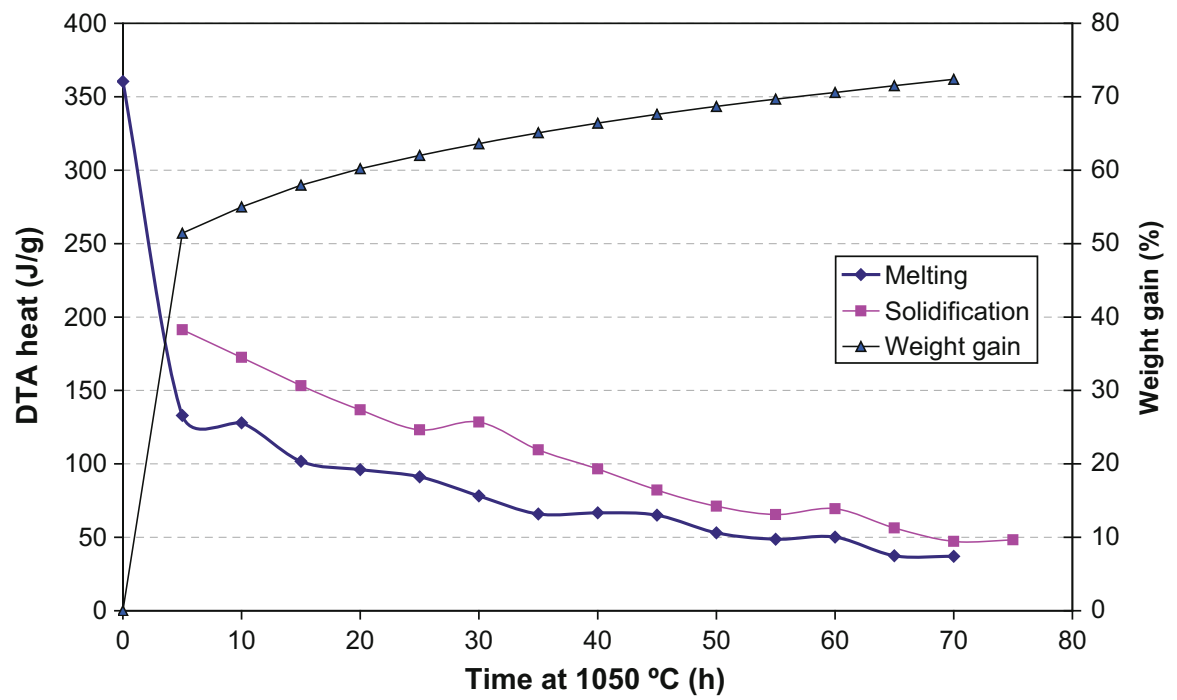

Fig. 11 TG-DTA analysis of multiple heating and cooling processes of aluminium particles at $1,050{ }^{\circ} \mathrm{C}$

The following changes in the slope suggest a structural change in the alumina layer, changing from gamma to alpha. This transformation can proceed directly or via intermediate, metastable phases $\left(\delta-\mathrm{Al}_{2} \mathrm{O}_{3}, \theta-\mathrm{Al}_{2} \mathrm{O}_{3}\right)$. Analysis of Figs. 8 and 9 suggests that both mechanisms are taking place. Part of $\gamma-\mathrm{Al}_{2} \mathrm{O}_{3}$ has been transformed into a metastable phase while the other transforms directly to $\alpha-\mathrm{Al}_{2} \mathrm{O}_{3}$. The formation of $\theta-\mathrm{Al}_{2} \mathrm{O}_{3}$ both in nano-size [4, 25, 28] and micro-size powders $[2,25]$ has been found, and it can appear in the studied powders. DTA (Fig. 9) shows at least two exothermic transformations, that makes difficult the analysis. The results obtained during heating are consistent with isothermal analysis. At $750{ }^{\circ} \mathrm{C}$, 
only $\gamma-\mathrm{Al}_{2} \mathrm{O}_{3}$ was found (Fig. 3a). Transformations during heating suggest a slightly higher temperature to start its transformation to $\theta-\mathrm{Al}_{2} \mathrm{O}_{3}$, and then to $\alpha-\mathrm{Al}_{2} \mathrm{O}_{3}$. The stabilization of this phase, according to the data of the derivative of TG (Fig. 9), takes place at temperatures above $950{ }^{\circ} \mathrm{C}$.

DTA results during cooling also reveal important information (Fig. 10). Two solidification peaks can sometimes be found, in particular when high temperatures are not achieved. This could probably be related to different particle sizes, although particle size distribution is narrow. Moreover, it can be appreciated how dwell time influences these solidification peaks, in particular the one found at higher temperature, which diminishes with dwell time. Small particles must be oxidized faster than large ones, and the molten aluminium inside them can be oxidized easier than in bigger particles.

In order to evaluate the time required for complete oxidation of aluminium particles, cyclic tests were carried out. This is important to obtain coatings with a shell structure outside within the whole Particoat project, and hence having thermal barrier effect. Powders were heated to the desired temperature, kept for a certain time, and then cooled to $50{ }^{\circ} \mathrm{C}$. The process was repeated several times, and melting and solidification peaks, and weight gain were measured. Figure 11 clearly shows how consecutive heating/cooling processes make aluminium inside particles melts and solidifies, becoming oxidized during heating at high temperature (i.e., $1,050{ }^{\circ} \mathrm{C}$ as shown in Fig. 11). After $75 \mathrm{~h}$ of oxidation at $1,050{ }^{\circ} \mathrm{C}$, the signal of solidification of molten aluminium still appears, indicating that the particles have not completely oxidized.

Figure 12 summarises the time required for the melting aluminium signal to disappear. As expected, melting aluminium disappears (gets oxidized) at shorter times when temperature is increased. Although very long times are required, complete oxidation of aluminium, in order to form hollow $\alpha-\mathrm{Al}_{2} \mathrm{O}_{3}$ spheres, can take place at $1,100{ }^{\circ} \mathrm{C}$. Only increasing the oxidation temperature by $50{ }^{\circ} \mathrm{C}$ reduces the time by half. And very short oxidation times are found at temperatures above $1,200{ }^{\circ} \mathrm{C}$.

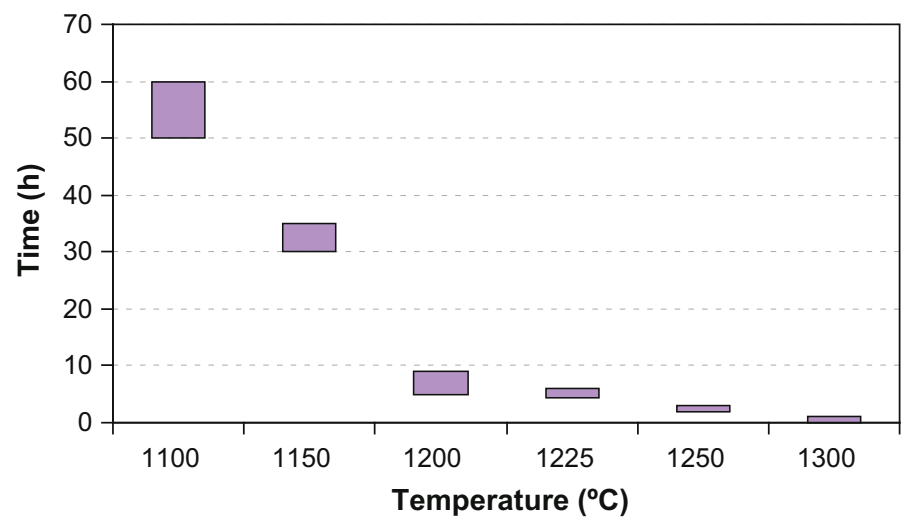

Fig. 12 Time required, during multiple heating and cooling processes of aluminium particles, for the disappearance of melting aluminium at different temperatures 

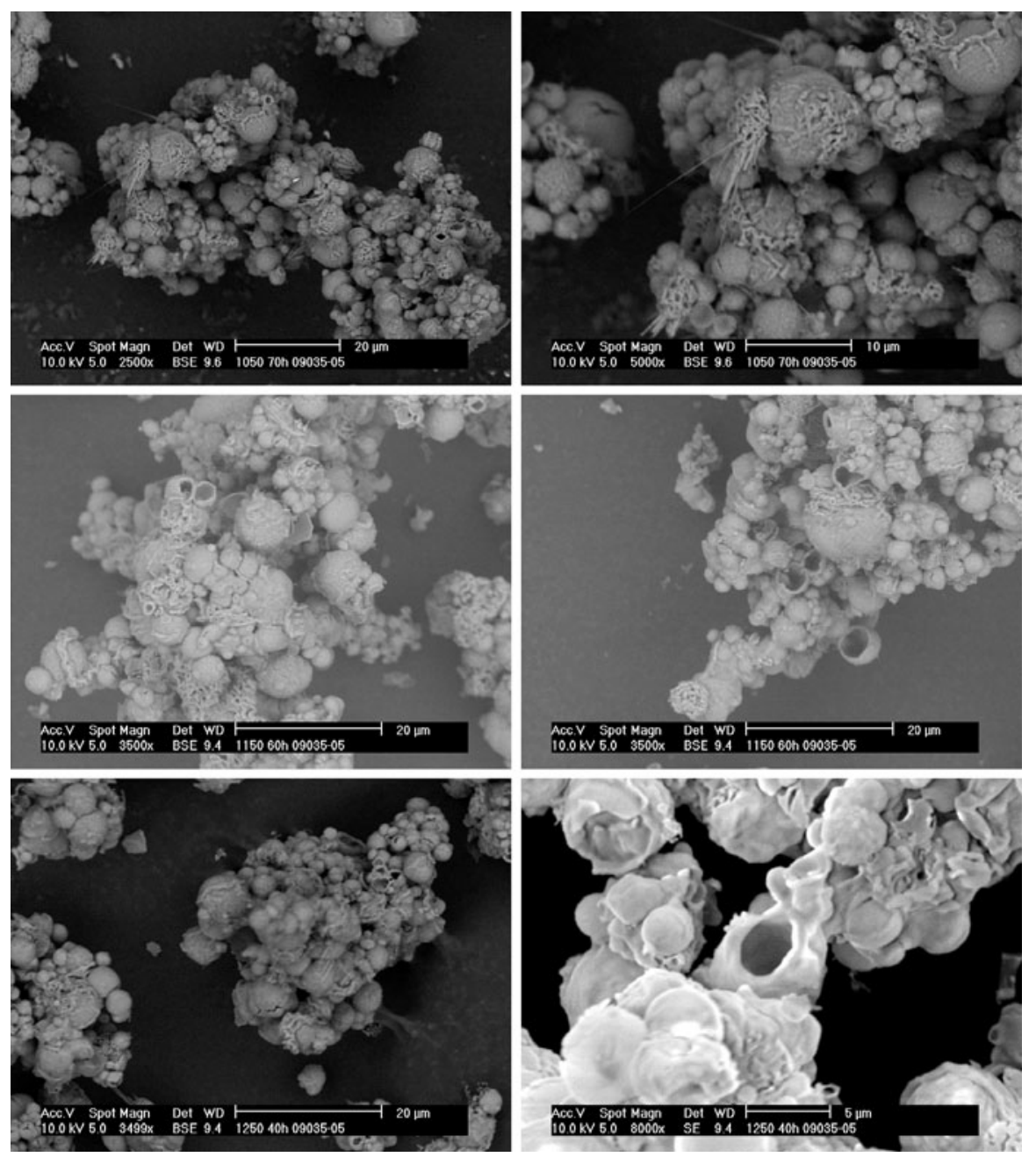

Fig. 13 SEM of aluminium powders after cyclical heating and cooling at $1,050{ }^{\circ} \mathrm{C}$ (above), $1,150{ }^{\circ} \mathrm{C}$ (center), and $1,250{ }^{\circ} \mathrm{C}$ (bottom)

Figure 13 shows the microstructure of aluminium powders after these cyclic treatments. At $1,150{ }^{\circ} \mathrm{C}$, torn particles are found, and alumina whiskers can be clearly appreciated. Some aluminium must be inside particles, although this cannot be appreciated, possibly due to alumina crust growth, which is now stiffer and, hence, brittle failure of particles does not take place. At 1,150 and $1,250{ }^{\circ} \mathrm{C}$, hollow spheres appear, and sintering of particles takes place. Oxidation is complete, and a limited number of particles are broken.

Long term tests were then carried out to find times for complete oxidation of particles, in order to relate them to activation energies. From results shown in Fig. 12, those tests were carried out at temperatures above $1,200{ }^{\circ} \mathrm{C}$. Times where 


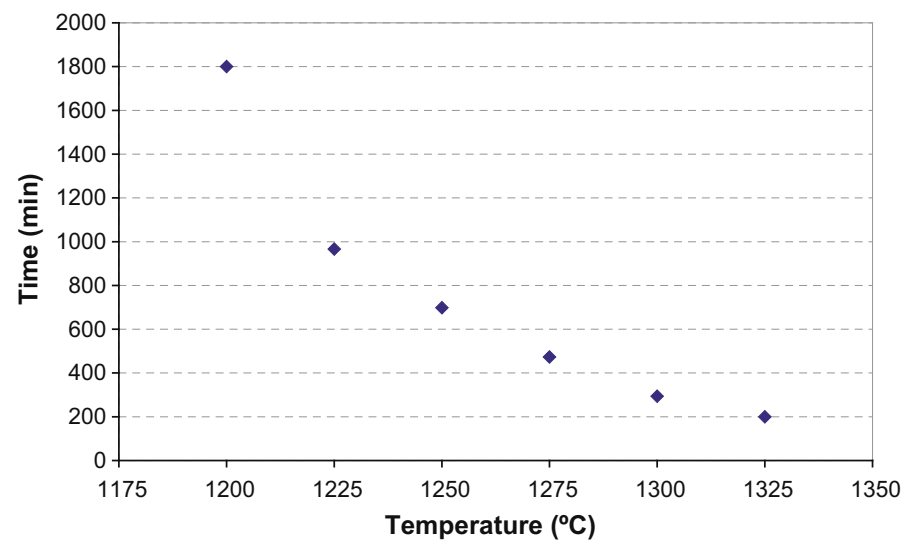

Fig. 14 Time for complete oxidation of aluminium powders at different temperatures

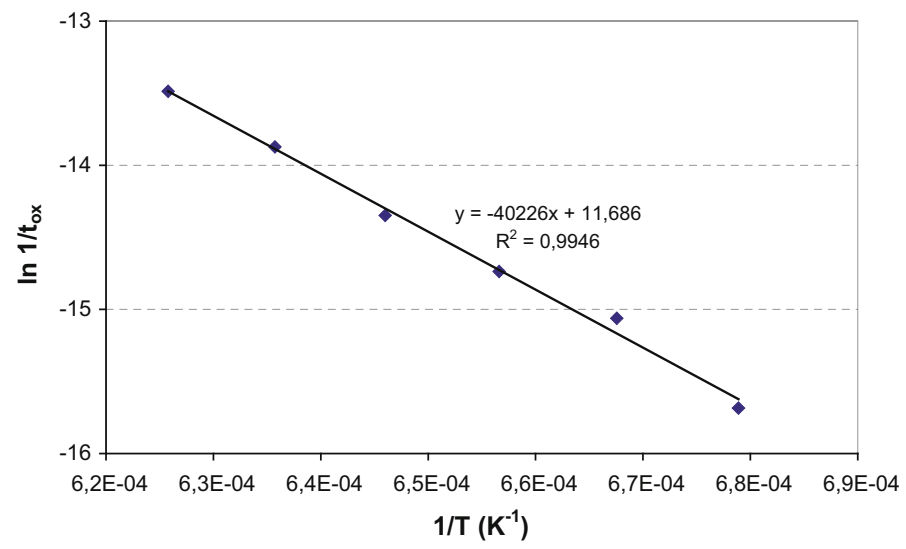

Fig. 15 Fitting of oxidation time versus oxidation temperature

mass gains are $88 \%$ (theoretical complete oxidation of aluminium) are shown in Fig. 14. As expected, time decreases with temperature. Those times are always a little higher than those shown in Fig. 12, as different properties are being plotted. If these data are plotted to check the possibility of these powders following an Arrhenius kinetic law, Fig. 15 is obtained. In this case, the inverse of time was selected as a way to measure reaction rate. The linearity of data is clear, and an adjustment with more than $99 \%$ goodness is obtained. This result can be transformed in activation energy of $\alpha-\mathrm{Al}_{2} \mathrm{O}_{3}$ growth, getting a value of $334 \mathrm{~kJ} / \mathrm{mol}$. This value is consistent with the values given by Trunov et al. [6], specially taking into account the strong influence of previous thermal history of powders. 


\section{Conclusions}

- Hollow spherical alumina particles were obtained after a complete oxidation process of aluminium microparticles.

- Amorphous to $\gamma-\mathrm{Al}_{2} \mathrm{O}_{3}$ transformation on the surface of aluminium particles has been quantified.

- $\gamma-\mathrm{Al}_{2} \mathrm{O}_{3}$ transforms to $\alpha-\mathrm{Al}_{2} \mathrm{O}_{3}$ both directly and through $\theta-\mathrm{Al}_{2} \mathrm{O}_{3}$, although their exact amount cannot be calculated.

- Times for complete oxidation of particles have been measured for different oxidation temperatures, thus calculating the activation energy of $\alpha-\gamma-\mathrm{Al}_{2} \mathrm{O}_{3}$ growth.

Acknowledgments This study was supported under the Project PARTICOAT (FP7-NMP-LARGE211329) funded by the European Union. All of the colleagues involved in the Project are also gratefully acknowledged.

\section{References}

1. B. Bouchaud, J. Balmain and F. Pedraza, Oxidation of Metals 69, 193 (2008).

2. M. A. Trunov, M. Schoenitz, X. Zhu and E. L. Dreizin, Combustion and Flame 140, 310 (2005).

3. L. P. H. Jeurgens, W. G. Sloog, F. D. Tichelaar and E. J. Mittemeijer, Physical Review B 62, 4707 (2000).

4. B. Rufino, F. Boulc'h, M. V. Coulet, G. Lacroix and R. Denoyel, Acta Materialia 55, 2815 (2007).

5. S. Hasani, M. Panjepour and M. Shamanian, Oxidation of Metals 78, 179 (2012).

6. M. A. Trunov, M. Schoenitz and E. L. Dreizin, Combustion Theory and Modelling 10, 603 (2006).

7. J. F. García, S. Sánchez and R. Metz, Oxidation of Metals 69, 317 (2008).

8. J. F. García-Martín, S. Sánchez and R. Metz, Oxidation of Metals 77, 1 (2012).

9. B. Rannou, M. Mollard, B. Bouchaud, J. Balmain, G. Bonnet, V. Kolarik and F. Pedraza, Defect and Diffusion Forum 323-325, 373 (2012).

10. F. Pedraza, M. Mollard, B. Rannou, J. Balmain, B. Bouchaud and G. Bonnet, Materials Chemistry and Physics 134, 700 (2012).

11. M. Mollard, B. Rannou, B. Bouchaud, J. Balmain, G. Bonnet and F. Pedraza, Corrosion Science 66, 118 (2013).

12. www.particoat.eu. Accessed April 2013.

13. B. Rannou, F. Velasco, S. Guzmán, V. Kolarik and F. Pedraza, Materials Chemistry and Physics 134, 360 (2012).

14. Y. F. Ivanov, M. N. Osmonoliev, V. S. Sedoi, V. A. Arkhipov, S. S. Bondarchuk, A. B. Vorozhstov, A. G. Korotkikh and V. T. Kuznetsov, Propellants, Explosives, Pyrotechnics 31, 401 (2006).

15. J. K. Odusote, L. A. Cornish and L. H. Chownand, Corrosion Science 63, 119 (2012).

16. R. Baboian (ed.), Corrosion Test and Standards Manual, (ASTM Manual Series, Fredericksburg, 1995), p. 149.

17. F. Velasco, A. González-Centeno and A. Bautista, Materials Science Forum 461-464, 1149 (2004).

18. F. Velasco, A. Bautista and A. González-Centeno, Corrosion Science 51, 21 (2009).

19. C. Moral and A. Bautista, Materials Science Forum 727-728, 108 (2012).

20. D. Naumenko, B. Gleeson, E. Wessel, L. Singheiser and W. J. Quadakkers, Metallurgical and Materials Transactions 38A, 2974 (2012).

21. G. C. Rybicki and J. L. Smialek, Oxidation of Metals 31, 275 (1989).

22. N. Babu, R. Balasubramaniam and A. Ghosh, Corrosion Science 43, 2239 (2001).

23. M. A. Montealegre, J. L. González-Carrasco and M. A. Muñoz-Morris, Intermetallics 9, 487 (2001).

24. Y. Wang, J. Xiong, J. Yan, H. Fan and J. Wang, Surface and Coatings Technology 206, 1277 (2011).

25. V. Kolarik, M. Juez-Lorenzo and H. Fietzek, Materials Science Forum 696, 290 (2011).

26. D. Naumenko, W. J. Quadakkers, A. Galerie, Y. Wouters and S. Jourdain, Materials at High Temperatures 20, 287 (2003). 
27. M. Schoenitz, B. Patel, O. Agboh and E. L. Dreizin, Thermochimica Acta 507-508, 115 (2010).

28. N. Eisenreich, H. Fietzek, M. M. Juez-Lorenzo, V. Kolarik, A. Koleczko and V. Weiser, Propellants, Explosives, Pyrotechnics 29, 137 (2004). 